\title{
Decentralized Voltage Balancing and Power Sharing in Islanded Bipolar DC Microgrids
}

\author{
Saman Dadjo Tavakoli, Mohsen Hamzeh, Keyhan Sheshyekani, and Gholamreza Kadkhodaei \\ Authors are with the Department of Electrical Engineering, Shahid Beheshti University, Tehran, Iran \\ Corresponding author: Saman Dadjo Tavakoli, e-mail: samandadjo@gmail.com
}

\begin{abstract}
This paper presents a decentralized control scheme for voltage balancing and power sharing in bipolar dc microgrids. This relies on utilizing a converter topology which offers three levels of output voltage availability with the key features of boosting the input voltage and balancing the output voltages. This converter makes it possible to further improve the structure of bipolar dc microgrids as it does not require a central voltage balancer. Small-signal analysis is done and system transfer functions are derived. Based on the RGA concept the highly coupled input-output pairs are found which helps with replacing the MIMO control system of the converter by two SISO systems. The appropriate voltage and current controllers are designed based on SISO principles. Moreover, a double droop control method is proposed which fulfills the simultaneous power sharing and voltage regulation of DG units in the host microgrid. The effectiveness of the proposed control strategy is demonstrated through simulation studies conducted on an islanded bipolar de microgrid involving unbalanced loads, while the voltage balancing of the bipolar dc microgrid and the power sharing accuracy are evaluated.
\end{abstract}

Keywords-Bipolar dc microgrid, bipolar boost converter, droop control, voltage balancer.

\section{INTRODUCTION}

DC microgrids are becoming more popular mainly due to the increase of power-electronic loads and the dc nature of the majority of distributed energy resources (DERs) such as PV, fuel cell, and wind generation systems [1],[2]. In fact, while microgrids are replete with dc loads, it is technically and economically preferred to feed these loads directly by $\mathrm{dc}$ DERs avoiding multiple conversion of voltage from dc to ac and vice versa. Moreover, dc microgrids are simpler to control as they need no frequency and reactive power regulations [3] [5].

Traditionally, the main focus of researches on dc power systems has been in the area of high-voltage dc power transmission systems (HVDC), where the continuous reduction in the price of power electronic devices has paved the way for further development in this area [6], [7]. In distribution level, data centres and navy shipboard are two areas where the replacement of conventional ac distribution networks with the zonal dc microgrids have been investigated. In both applications, many advantages, including higher efficiency and improved reliability are associated with the use of dc microgrids [3], [8], [9].

Recently, bipolar dc microgrids have been proposed offering additional benefits compared to the conventional dc microgrids [10]. Some of the challenges associated with bipolar dc microgrid have been extensively investigated as they are common between conventional dc microgrids and bipolar dc microgrids. However, there are some issues including power sharing, voltage balancing, and voltage stability which need to be specifically investigated for bipolar dc microgrids.

Within this context, this paper focuses on the voltage balancing of bipolar dc microgrids while proposing a doubledroop power sharing method. To this aim, we use a bipolar $\mathrm{dc} / \mathrm{dc}$ boost converter topology which provides the possibility of performing the voltage balancing in a decentralized fashion. Although a decentralised voltage-balancing scheme has been proposed in [11], the main focus was given to the control system of $\mathrm{z}$-source converter. In this paper, small-signal analysis is done to obtain the transfer functions. From the Relative Gain Array (RGA) analysis, the Multi-Input MultiOutput (MIMO) converter model is replaced by two distinct Single-Input Single-Output (SISO) systems. Hence, the voltage and current controllers are designed based on the control principles of SISO systems. The bipolar boost converter provides the possibility of adopting a double droop control method to fulfill the simultaneous power sharing and voltage regulation of DG units in the host microgrid.

The paper is organized as follows: in section 2, we provide a cursory review about the bipolar dc microgrids and their operation principles, while the voltage balancing issue in this type of microgrids is discussed. In section 3, the small-signal analysis is carried out. The design of voltage and current controllers and the power-sharing scheme for bipolar boost converter are explained in section 4. Finally, an islanded bipolar dc microgrid is simulated and studied in section 5 .

\section{OVERVIEW OF BIPOLAR DC MICROGRIDS AND VOLTAGE BALANCING CHALLENGE}

The typical topology of a bipolar dc microgrid is presented in Fig.1(a) whose salient feature is the availability of two voltage levels including $V_{d c}$ and $2 V_{d c}$, distributed by three wires throughout the microgrid. The bipolar dc microgrid can be considered as an effective solution to the applications where a high level of reliability and efficiency is required. In this type of microgrid, in case of loss of one wire, the microgrid continues to supply the loads connected between two remaining wires. Furthermore, it is possible to connect each of loads to both terminals; while one terminal feeds the 


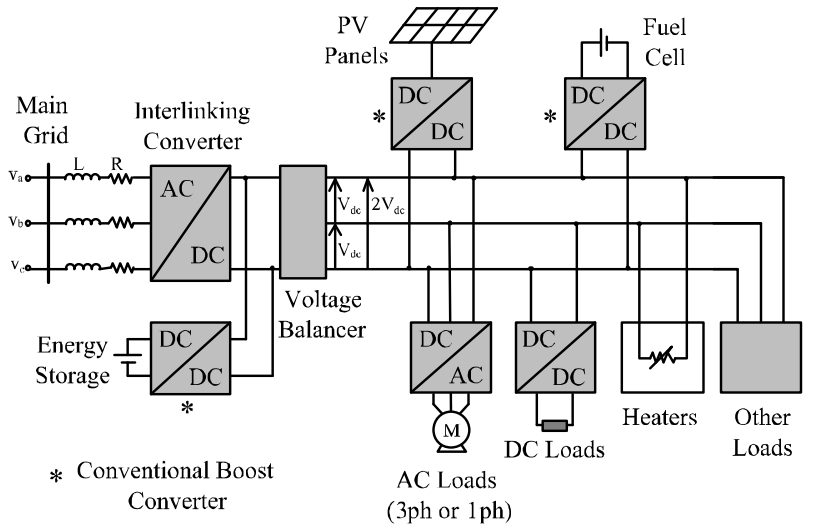

(a)

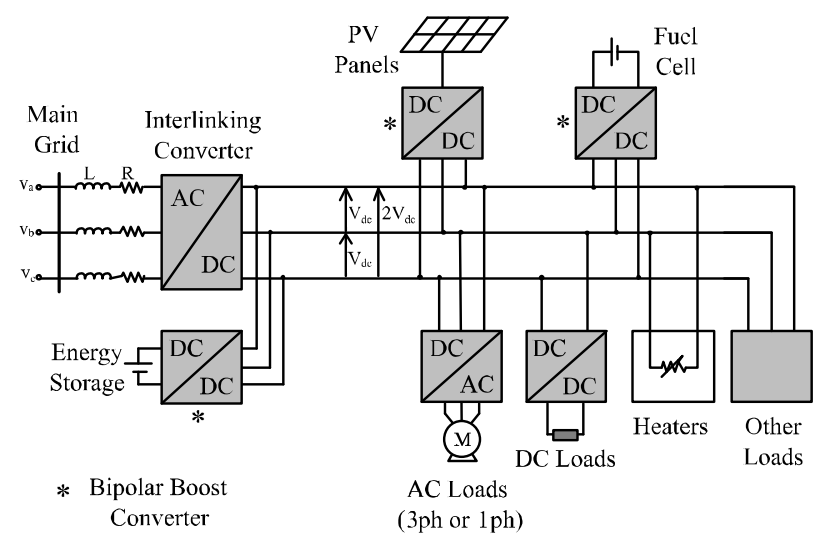

Fig. 1. Bipolar dc microgrid, (a) conventional topology, and (b) proposed configuration without central voltage balancer.

load, the other is kept as the spare terminal. Hence, if one terminal is lost, the load supply can be switched to the other terminal. Providing two voltage levels, heavy loads can be connected to $2 V_{d c}$ which in turn reduces the ohmic power losses to the half.

The original topology of bipolar dc microgrids requires a central voltage balancer aiming to keep the voltages of upper and lower terminals equal, in particular, under unbalanced loading. Hence, any malfunction in the central voltage balancer may affect the overall functionality of the whole microgrid. To cope with this problem, this paper proposes a distributed voltage-balancing strategy in which all DERs play their own role as shown in Fig.1(b). It is obvious that the conventional $\mathrm{dc} / \mathrm{dc}$ boost converters, interfacing dc sources to the microgrid, are not capable of performing the voltage balancing duty, as they have only two wires at the output terminals.

So far, several topologies have been proposed to perform voltage-balancing function, some of them are able to buck their input voltages as well [12], [13]. However, to the best of our knowledge, no small-signal analysis is available for these

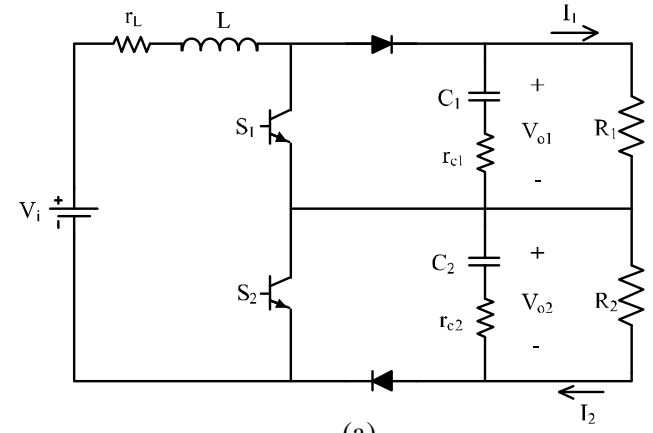

(a)

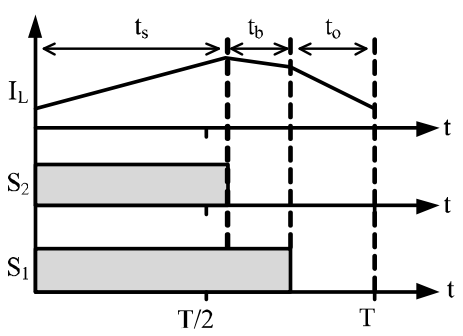

(b)

Fig. 2. Bipolar boost converter, (a) topology, and (b) switching pattern.

topologies. Moreover, rather than buck converters, integrating the voltage balancing function with the boost converters is essentially preferred as the majority of DERs require boost converters for interfacing with the grid. Technically, a variety of dc/dc high-step-up (boost) converter topologies can be employed to incorporate voltage-balancing function into their controllers. However, those converters with two capacitors at their output terminals, such as three-level boost converter [14], [15], two-inductor boost converter [16], or interleaved boost converter with coupled inductors [17], are easier to be modified to fulfill the voltage-balancing function.

Three-level boost converter has originally been proposed to reduce the voltage stress on power switches by 50 percent as compared with the conventional boost converter [14]. In [18], authors developed an interleaved version of the threelevel boost converter which balances the neutral-point potential mainly to cope with the neutral-point drifting problem. In this paper, for the integration in bipolar $\mathrm{dc}$ microgrids, the design of the conventional three-level boost converter is changed so that it fulfills the proposed voltagebalancing strategy, in particular, in the presence of unbalanced loads.

\section{MODELLING AND SMALL-SIGNAL ANALYSIS}

The bipolar boost converter is shown in Fig.2(a). As known, in the original topology only two wires are available at the output terminal. However, for the application in bipolar dc microgrid, we extend the neutral point in order to serve as the zero-potential wire in the grid. Referring to the switching 
times of $S_{1}$ and $S_{2}$, as they are shown in Fig.2(b), the converter has the following three distinctive states:

$\mathrm{t}_{\mathrm{s}}$ ) ON-state: both $\mathrm{S}_{1}$ and $\mathrm{S}_{2}$ are $\mathrm{ON}$, and the shoot-through current passes through the inductor $L$. During this state, the load currents are supplied by the capacitors $C_{1}$ and $C_{2}$.

$\mathrm{t}_{\mathrm{b}}$ ) Balancing-state: balancing function of the converter is activated in this state. If $R_{1}<R_{2} \quad\left(R_{1}\right.$ absorbs more current), $S_{1}$ is OFF and $S_{2}$ is kept ON. Alternatively, if $R_{1}>R_{2}, \mathrm{~S}_{1}$ is kept $\mathrm{ON}$ and $\mathrm{S}_{2}$ is OFF.

$\mathrm{t}_{\mathrm{o}}$ ) OFF-state: both $\mathrm{S}_{1}$ and $\mathrm{S}_{2}$ are OFF, and the inductor's energy discharges into $R_{1}$ and $R_{2}$.

It is worth mentioning that the output voltages $V_{o 1}$ and $V_{o 2}$ are affected concurrently by changes in the duty cycles of both $S_{1}$ and $S_{2}$; nonetheless, the duty cycles of $S_{1}$ and $S_{2}$ have more significant effect on $V_{o 2}$ and $V_{o 1}$, respectively. To design the voltage and current controllers, small-signal analysis is required in order to obtain the transfer functions [19]. The dc input-to-output transfer functions can be achieved by conducting simple circuit analysis on the dc equivalent circuit of the converter, which is shown in Fig.3(a). The inputto-output transfer functions are

$$
\begin{aligned}
& \frac{V_{o 1}}{V_{I}}=\frac{1}{1-D_{1}} \frac{1}{1+\left(\frac{1-D_{2}}{1-D_{1}}\right)^{2} \frac{R_{2}}{R_{1}}+\frac{r_{L}}{\left(1-D_{1}\right)^{2} R_{1}}} \\
& \frac{V_{o 2}}{V_{I}}=\frac{1}{1-D_{2}} \frac{1}{1+\left(\frac{1-D_{1}}{1-D_{2}}\right)^{2} \frac{R_{1}}{R_{2}}+\frac{r_{L}}{\left(1-D_{2}\right)^{2} R_{2}}}
\end{aligned}
$$

where $D_{1}$ and $D_{2}$ are the nominal duty cycles of $S_{1}$ and $S_{2}$ respectively. The loads connected to upper and lower terminals are, respectively, denoted by $R_{1}$ and $R_{2}$. Fig.3(b) shows the small-signal equivalent circuit based on which the small-signal transfer functions are derived. In this circuit, lower case letters represent the small-signal values, while capital letters correspond to dc values. $i_{o 1}, i_{o 2}$, and $v_{i}$ are the small-signal variation of the output currents and the input voltage at the given operating points. By doing circuit analysis on the equivalent circuit shown in Fig.3(b), the transfer functions relating $v_{o 1}$ to $d_{1}$ and $d_{2}$ are derived

$$
T_{P 11}(s)=\frac{v_{o 1}}{d_{1}}=\frac{V_{o 1}\left(1-\frac{Z_{l}(s)}{\left(1-D_{1}\right)^{2} R_{1}}-\frac{\left(1-D_{2}\right)^{2} Z_{2}(s)}{\left(1-D_{1}\right)^{2} R_{1}}\right)}{\frac{Z_{l}(s)}{\left(1-D_{1}\right) Z_{1}(s)}+(1-D 1)+\frac{\left(1-D_{2}\right)^{2} Z_{2}(s)}{\left(1-D_{1}\right) Z_{1}(s)}}(3)
$$

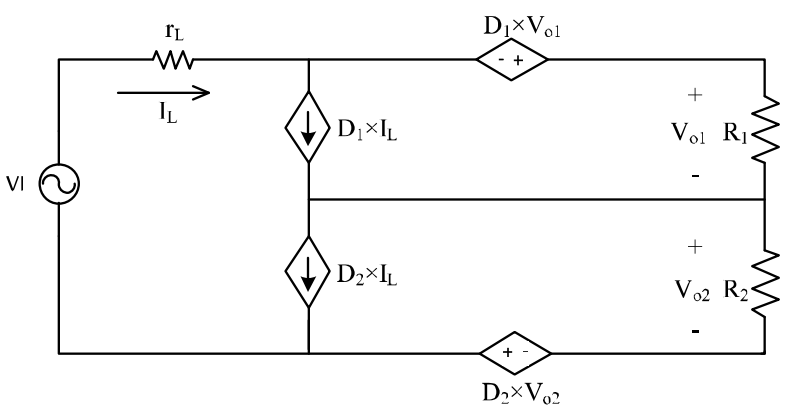

(a)

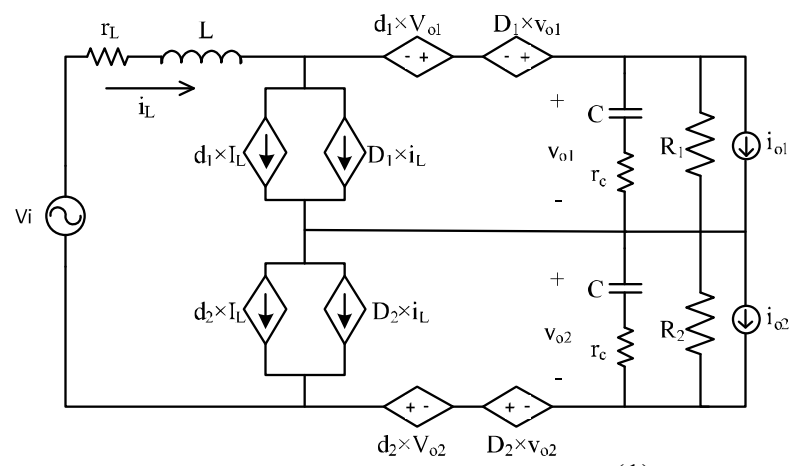

(b)

(1)

Fig. 3. Equivalent circuit of the bipolar boost converter, (a) dc equivalent circuit, and (b) small-signal equivalent circuit.

$T_{P 12}(s)=\frac{v_{o 1}}{d_{2}}=\frac{V_{o 1}\left(\frac{\left(1-D_{2}\right) Z_{2}(s)}{\left(1-D_{1}\right) R_{1}}+\frac{\left(1-D_{2}\right) \breve{R}_{2}^{\prime}}{\left(1-D_{1}\right) R_{1}}\right)}{\frac{Z_{l}(s)}{\left(1-D_{1}\right) Z_{1}(s)}+(1-D 1)+\frac{\left(1-D_{2}\right)^{2} Z_{2}(s)}{\left(1-D_{1}\right) Z_{1}(s)}}$

where

$$
\begin{aligned}
& Z_{1}(s)=\frac{R_{1}\left(r_{c}+\frac{1}{s C}\right)}{R_{1}+\left(r_{c}+\frac{1}{s C}\right)} \\
& Z_{2}(s)=\frac{R_{2}\left(r_{c}+\frac{1}{s C}\right)}{R_{2}+\left(r_{c}+\frac{1}{s C}\right)} \\
& Z_{l}(s)=r_{L}+s L
\end{aligned}
$$

The converter's output impedance, seen from the upper terminal, and the input-to-output transfer functions are $M_{v 1}(\mathrm{~s})=\frac{v_{o 1}}{v_{i}}=$

$\frac{1}{\frac{Z_{l}(s)}{\left(1-\mathrm{D}_{1}\right) \mathrm{Z}_{1}(\mathrm{~s})}+\left(1-D_{1}\right)+\left(1-\mathrm{D}_{2}\right) \frac{Z_{2}(\mathrm{~s})}{Z_{1}(\mathrm{~s})}\left(1+\frac{D_{1}-D_{2}}{1-D_{1}}\right)}$




$$
Z_{o 1}(s)=\frac{v_{o 1}}{i_{o 1}}=\frac{1}{\frac{1}{Z_{1}(s)}+\frac{\left(1-D_{1}\right)^{2}}{Z_{l}(s)+Z_{2}(s)\left(1-D_{2}\right)^{2}}}
$$

Following the same procedure, the transfer functions relating $v_{o 2}$ to $d_{2}$ and $d_{1}$ are obtained

$$
\begin{gathered}
T_{P 22}(s)=\frac{v_{o 2}}{d_{2}}=\frac{V_{o 2}\left(1-\frac{Z_{l}(s)}{\left(1-D_{2}\right)^{2} R_{2}}-\frac{\left(1-D_{1}\right)^{2} Z_{1}(s)}{\left(1-D_{2}\right)^{2} R_{2}}\right)}{\frac{Z_{l}(s)}{\left(1-D_{2}\right) Z_{2}(s)}+(1-D 2)+\frac{\left(1-D_{1}\right)^{2} Z_{1}(s)}{\left(1-D_{2}\right) Z_{2}(s)}} \\
T_{P 21}(s)=\frac{v_{o 2}}{d_{1}}=\frac{V_{o 2}\left(\frac{\left(1-D_{1}\right) Z_{1}(s)}{\left(1-D_{2}\right) R_{2}}+\frac{\left(1-D_{1}\right) R_{1}}{(1-D 2) R_{2}}\right)}{\frac{Z_{l}(s)}{\left(1-D_{2}\right) Z_{2}(s)}+(1-D 2)+\frac{\left(1-D_{1}\right)^{2} Z_{1}(s)}{\left(1-D_{2}\right) Z_{2}(s)}}
\end{gathered}
$$

The input-to-output and output impedance transfer functions, seen from the lower terminal, are respectively given in (4) and

$$
\begin{aligned}
& M_{v 2}(\mathrm{~s})=\frac{v_{o 2}}{v_{i}}= \\
& \frac{Z_{l}(s)}{\left(1-\mathrm{D}_{2}\right) Z_{2}(\mathrm{~s})}+\left(1-D_{2}\right)+\left(1-\mathrm{D}_{1}\right) \frac{Z_{1}(\mathrm{~s})}{Z_{2}(\mathrm{~s})}\left(1+\frac{D_{2}-D_{1}}{1-D_{2}}\right) \\
& Z_{o 2}(s)=\frac{v_{o 2}}{i_{o 2}}=\frac{1}{\frac{1}{Z_{2}(s)}+\frac{\left(1-D_{2}\right)^{2}}{Z_{l}(s)+Z_{1}(s)\left(1-D_{1}\right)^{2}}}
\end{aligned}
$$

The transfer function model of the converter including the voltage controllers is shown in Fig.4. The small-signal value of the reference voltage is $v_{r}$, which is treated as disturbance, along with $i_{o 1}, i_{o 2}$, and $v_{i}$. The feedback gain is shown by $\beta$ which scales down the measured terminal voltages. It should benoted that $T_{P 11}(s), T_{P 12}(s), T_{P 22}(s)$, and $T_{P 21}(s)$ represent the plant's transfer functions, however, $T_{P 21}(s)$ (and $d_{1}$ ) has more significant effect on $v_{o 2}$ while $T_{P 12}(s)$ (and $d_{2}$ ) contributes more to $v_{o 1} . T_{C 1}(s)$ and $T_{C 2}(s)$ are the voltage controllers which will be designed in the next section. As it can be seen from Fig. 4, the converter is a multi-input-multioutput (MIMO) system, with two inputs of $d_{1}$ and $d_{2}$, and two outputs of $v_{o 1}$ and $v_{o 2}$. The converter can be described by the following matrix equation:

$\left(\begin{array}{c}v_{o 1} \\ v_{o 2}\end{array}\right)=\left(\begin{array}{cc}T_{p 11}(s) & T_{p 2}(s) \\ T_{p 21}(s) & T_{p 22}(s)\end{array}\right)+\left(\begin{array}{l}M_{v 1}(\mathrm{~s}) \\ M_{v 2}(\mathrm{~s})\end{array}\right) v_{i}-\left(\begin{array}{cc}Z_{o 1}(\mathrm{~s}) & 0 \\ 0 & Z_{o 2}(\mathrm{~s})\end{array}\right)\left(\begin{array}{l}i_{o 1} \\ i_{o 2}\end{array}\right)$
TABLE 1. CONVERTER OPERATING POINT DATA.

\begin{tabular}{|c||c|}
\hline Parameter & Operating-point Value \\
\hline \hline$V_{i n}$ & $200 \mathrm{~V}$ \\
\hline$V_{o 1}, V_{o 2}$ & $400 \mathrm{~V}$ \\
\hline$L, r_{L}$ & $474 \mu \mathrm{H}, 0.3 \Omega$ \\
\hline$C, r_{c}$ & $50 \mu \mathrm{F}, 0.13 \Omega$ \\
\hline$D_{1}, D_{2}$ & 0.5 \\
\hline$R_{1 \text { min }}, R_{2 \text { min }}$ & $32 \Omega$ \\
\hline$f_{s}$ & $100 \mathrm{khz}$ \\
\hline
\end{tabular}

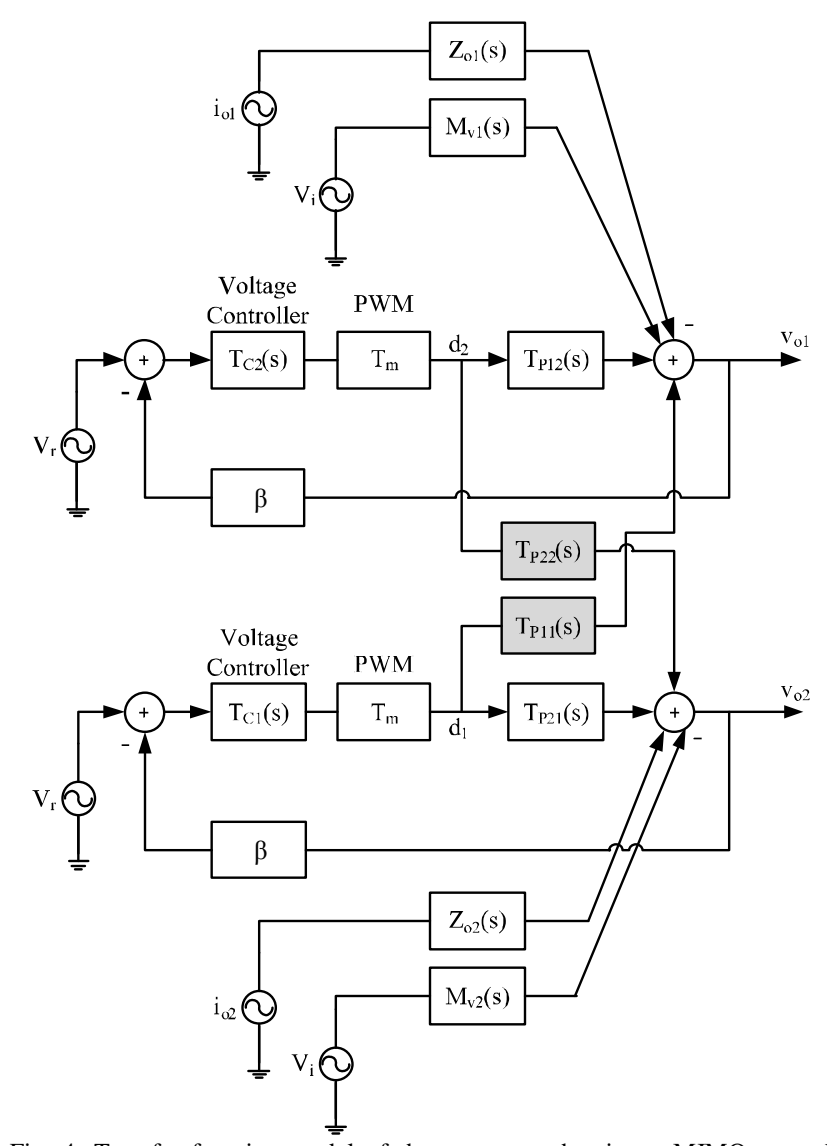

Fig. 4. Transfer function model of the converter showing a MIMO control system.

Values of the capacitors and inductor are given in Table 1, which are chosen to satisfy the design criteria for keeping the converter in the continuous conduction mode and limiting the output voltage ripple below one percent of the nominal voltage. It should be noted that at the operating point, $D_{1}$ and $D_{2}$ are equal, since the converter is supposed to have the equal output voltages in the steady state condition. By 
substituting the values given in Table 1 in (3), (4), and (8) (13), the transfer functions at the operating point are obtained:

$$
\begin{gathered}
T_{P 11}(s)=T_{P 22}(\mathrm{~s})= \\
\frac{-3.23 s^{3}-4.47 \times 10^{5} s^{2}+7.74 \times 10^{9} s-1.96 \times 10^{11}}{s^{3}+2014 s^{2}+2.22 \times 10^{7} s+1.33 \times 10^{10}} \\
T_{P 12}(\mathrm{~s})=\mathrm{T}_{P 21}(\mathrm{~s})=\frac{5.48 \times 10^{4} s^{2}+8.5 \times 10^{9} s+1.04 \times 10^{13}}{s^{3}+2014 s^{2}+2.22 \times 10^{7} s+1.33 \times 10^{10}} \\
Z_{o 1}(\mathrm{~s})=\mathrm{Z}_{o 2}(s)= \\
\frac{0.12 s^{3}+2 \times 10^{4} s^{2}+7.74 \times 10^{9} s+2.17 \times 10^{11}}{s^{3}+2014 s^{2}+2.22 \times 10^{7} s+1.33 \times 10^{10}} \\
M_{v 1}(\mathrm{~s})=\mathrm{M}_{v 2}(\mathrm{~s})=\frac{136.6 s+2.1 \times 10^{7}}{s^{2}+1392 s+2.14 \times 10^{7}}
\end{gathered}
$$

\section{DESCRIPTION OF THE PROPOSED STRATEGY}

Making reference to (14), the converter is considered as a MIMO system. Hence the MIMO design principles should be normally used to design the voltage and current controllers. Nonetheless, in case of weak interaction between certain inputs $\left(d_{1}\right.$ or $\left.d_{2}\right)$ and outputs $\left(v_{o 1}\right.$ or $\left.v_{o 2}\right)$, it is possible to decouple the MIMO system and treat it with SISO analysis techniques. The degree of coupling or interaction can be determined by Relative Gain Array (RGA) . Having the matrix transfer function of the converter (19), each element of the RGA matrix is defined as (20),

$$
\begin{aligned}
G(\mathrm{~s})= & \left(\begin{array}{ll}
T_{P 11}(\mathrm{~s}) & T_{P 12}(\mathrm{~s}) \\
T_{P 21}(\mathrm{~s}) & T_{P 22}(\mathrm{~s})
\end{array}\right) \\
& \lambda_{i j}=[G(0)]_{i j}\left[G^{-1}(0)\right]_{j i}
\end{aligned}
$$

where $[G(0)]_{i j}$ and $\left[G^{-1}(0)\right]_{j i}$ are the $i j^{\text {th }}$ element of the converter dc gain matrix and the $j i^{t h}$ element of the inverse of the dc gain matrix respectively. The detailed procedure of calculating RGA is presented in [20]. The calculated RGA matrix is given in (21).

$$
\begin{aligned}
& d_{1} \quad d_{2} \\
& v_{o 1}\left(\begin{array}{cc}
-0.0004 & 1.0004 \\
1.0004 & -0.0004
\end{array}\right)
\end{aligned}
$$

Rows and columns of the obtained RGA matrix are associated with the outputs and inputs, respectively. The small diagonal values imply weak interactions between the two input-output pairs of $v_{o 1}-d_{1}$, and $v_{o 2}-d_{2}$. Therefore, it would be legitimate to consider the converter as a decoupled MIMO system in which $v_{o 1}-d_{2}$ and $v_{o 2}-d_{1}$ are the outputinput pairs. In this decoupled system, SISO design techniques can be applied.

\section{A. voltage controller}

Ignoring the effects of $T_{P 11}(s)$ and $T_{P 22}(s)$ on the output voltages, the voltage controller can be derived for each

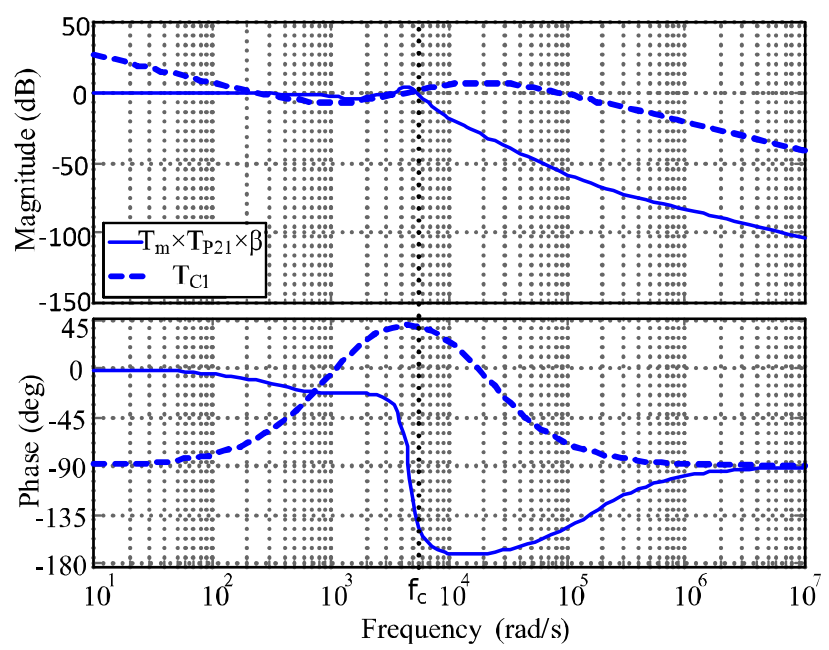

Fig. 5. Bode plots of voltage controller and loop gain transfer functions.

terminal independently. Plant transfer functions $T_{P 12}(s)$ and $T_{P 21}(s)$ are used to design the independent voltage controllers regulating $v_{o 1}$ and $v_{o 2}$ receptively. The design procedure is quite straightforward. The voltage controller is a lead controller whose duty is to provide a high gain crossover frequency $f_{c}$, while maintaining a phase margin (PM) of the order of 45-60deg [21]. The loop-gain transfer function for the lower terminal can be written as,

$$
|T(s)|=\left|T_{C 1}(s)\right| \times\left|T_{m}(s)\right| \times\left|T_{P 21}(s)\right| \times \beta
$$

where $T_{m}$ is a constant-gain transfer function of the PWM generator and is equal to 0.2 . Feedback gain $\beta$ is equal to 0.00625 . At the crossover frequency $f_{c}=4.43 \times 10^{3} \mathrm{rad} / \mathrm{sec}$, the integral-double-lead controller is obtained which is essentially similar to $T_{C 2}(s)$.

$$
T_{C 1}(s)=\frac{89.4 \times 10^{3}(s+986.8)^{2}}{s\left(s+19.8 \times 10^{3}\right)^{2}}
$$

Fig.5 shows the frequency response of $T_{C 1}$ and $T_{m}(s) \times T_{P 21}(s) \times \beta$. As it can be seen, the controller provides a phage margin of more than $45 \mathrm{deg}$ at the crossover frequency $f_{c}$.

\section{B. current controller}

In the grid-connected mode, the converter's terminal voltages are imposed by the grid. So, it is favourable to have the converter work in the current-control mode. In this mode, the converter should inject certain currents dictated by the references. In order to design an appropriate current controller, 
we need to derive control-to-output transfer functions which reveal the interactions between the duty cycles (i.e., $D_{1}$ and $D_{2}$ ) and each terminal of the converter. Performing circuit analysis on the equivalent circuit shown in Fig.3(b) leads to the following transfer functions:

$$
\begin{gathered}
T_{I 11}(s)=\frac{i_{1}}{d_{1}}=\frac{V_{o 1}\left(1-\frac{R_{2} Z_{2}(s)\left(1-D_{2}\right)}{R_{1}\left(1-D_{1}\right)^{2}}-\frac{Z_{l}(s)}{R_{1}\left(1-D_{1}\right)^{2}}\right)}{\frac{Z_{l}(s)}{Z_{1}(s)\left(1-D_{1}\right)}+R_{1}+\frac{R_{2} Z_{2}(s)\left(1-D_{2}\right)}{Z_{1}(s)\left(1-D_{1}\right)}} \\
T_{I 12}(s)=\frac{i_{1}}{d_{2}}=\frac{V_{o 1}\left(\frac{R_{2}(1-D 2)}{R_{1}\left(1-D_{1}\right)}+\frac{R_{2} Z_{2}(s)}{R_{1}\left(1-D_{1}\right)}\right)}{\frac{Z_{l}(s)}{Z_{1}(s)\left(1-D_{1}\right)}+R_{1}+\frac{R_{2} Z_{2}(s)\left(1-D_{2}\right)}{Z_{1}(s)\left(1-D_{1}\right)}} \\
T_{I 22}(s)=\frac{i_{2}}{d_{2}}=\frac{V_{o 2}\left(1-\frac{R_{1} Z_{1}(s)\left(1-D_{1}\right)}{R_{2}\left(1-D_{2}\right)^{2}}-\frac{Z_{l}(s)}{Z_{2}\left(1-D_{2}\right)^{2}}\right)}{Z_{2}(s)\left(1-D_{2}\right)}+R_{2}+\frac{R_{1} Z_{1}(s)\left(1-D_{1}\right)}{Z_{2}(s)\left(1-D_{2}\right)} \\
T_{I 21}(s)=\frac{i_{2}}{d_{1}}=\frac{\frac{V_{o 2}\left(\frac{R_{1}\left(1-D_{1}\right)}{R_{2}\left(1-D_{2}\right)}+\frac{R_{1} Z_{1}(s)}{R_{2}\left(1-D_{2}\right)}\right)}{Z_{l}(s)}+R_{2}+\frac{R_{1} Z_{1}(s)\left(1-D_{1}\right)}{Z_{2}(s)\left(1-D_{2}\right)}}{Z_{2}(s)\left(1-D_{2}\right)}
\end{gathered}
$$

where $Z_{1}(s), Z_{2}(s)$, and $Z_{l}(s)$ are given in (28), (29), and (7), respectively.

$$
\begin{aligned}
& Z_{1}(s)=\frac{\left(r_{c}+\frac{1}{s C}\right)}{R_{1}+\left(r_{c}+\frac{1}{s C}\right)} \\
& Z_{2}(s)=\frac{\left(r_{c}+\frac{1}{s C}\right)}{R_{2}+\left(r_{c}+\frac{1}{s C}\right)}
\end{aligned}
$$

Substituting the operating-point values given in Table 1 in (27) and (25) and ignoring the effect of (24) and (26) on $i_{1}$ and $i_{2}$ respectively, the control-to-output transfer functions can be written as,

$$
T_{I 12}(\mathrm{~s})=T_{I 21}(\mathrm{~s})=\frac{1721 s^{2}+2.6 \times 10^{8} s+4.9 \times 10^{11}}{s^{3}+2151 s^{2}+4.3 \times 10^{7} s+2.6 \times 10^{10}}
$$

From (30), the current controller can be designed at the crossover frequency of the loop gain. At $f_{c}=9.7 \times 10^{3} \mathrm{rad} / \mathrm{sec}$, the controller of (31) provides a phase margin of $60 \mathrm{deg}$. It should be noted that the current controllers of $T_{C I 1}(s)$ and $T_{C I 2}(s)$ are essentially the same.

$$
T_{C I 1}(\mathrm{~s})=\frac{2.7 \times 10^{5} s^{2}+1 \times 10^{9} s+9.1 \times 10^{11}}{s^{3}+1 \times 10^{5} s^{2}+2.6 \times 10^{9} s}
$$

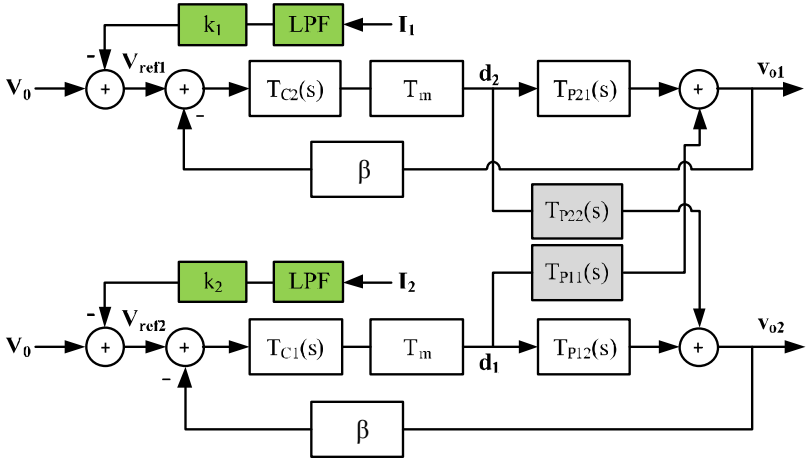

Fig. 6. Voltage control loops of the converter with the addition of two droop gains.

\section{C. power sharing scheme}

One of the interesting features of the bipolar boost converter is the possibility of implementing two droop controllers for each converter. As the upper and lower terminals of bipolar boost converter can be considered decoupled, as described by (21), one droop controller can be used to modify the reference voltage of the upper terminal, and the other to modify the lower terminal's reference voltage. Droop gains can be obtained

$$
k_{1}=k_{2}=\frac{V_{0}-V_{f l}}{I_{f l}}
$$

where $V_{0}$ is the no-load voltage, while the full-load voltage (or the lowest allowable voltage) is $V_{f l} . I_{f l}$ is the full-load current of each terminal (for example, if the rated power of the converter is $10 \mathrm{~kW}$, the power of each terminal will be $5 \mathrm{~kW}$, which will have the full-load current of $12.5 \mathrm{~A}$ ). The two droop gains $k_{1}$ and $k_{2}$ will then be used to calculate voltage reference for the upper and lower terminals of the converter,

$$
\begin{aligned}
& V_{r e f 1}=V_{0}-k_{1} \times I_{1} \\
& V_{r e f 2}=V_{0}-k_{2} \times I_{2}
\end{aligned}
$$

where $V_{\text {ref } 1}$ and $V_{\text {ref } 2}$ are the reference voltages of control loops. $I_{1}$ and $I_{2}$ are, respectively, the upper and lower terminals' currents (see Fig.6) passing through low-pass filters with the cutoff frequency of $5 \mathrm{~Hz}$ in order to remove highfrequency ripples.

\section{Simulation Results}

An islanded bipolar dc microgrid consisting of three DGs and five dc loads is shown in Fig.7. The rated power of both DG\#1 and DG\#2 is $10 \mathrm{~kW}$ which are connected to the microgrid by means of bipolar boost converters. So, each terminal of their respective converters can supply $5 \mathrm{~kW}$ to the grid. DG\#3 is also connected to the microgrid by the bipolar boost converter; 
TABLE 2. LOAD POWER AND ASSOCIATED SWITCHING TIME.

\begin{tabular}{|c||c|c||c|}
\hline Load & $\mathbf{P}(\mathbf{k W})$ & $\mathbf{I}(\mathbf{A})$ & $\begin{array}{c}\text { Switching times } \\
\text { (sec) }\end{array}$ \\
\hline \hline Load\#1 & 6 & 15 & 0 \\
\hline Load\#2 & 3 & 7.5 & 0 \\
\hline Load\#3 & 2 & 5 & $0.4,0.85$ \\
\hline Load\#4 & 4 & 10 & $0.55,0.85$ \\
\hline Load\#5 & 5 & 6.25 & $0.0,0.7$ \\
\hline
\end{tabular}

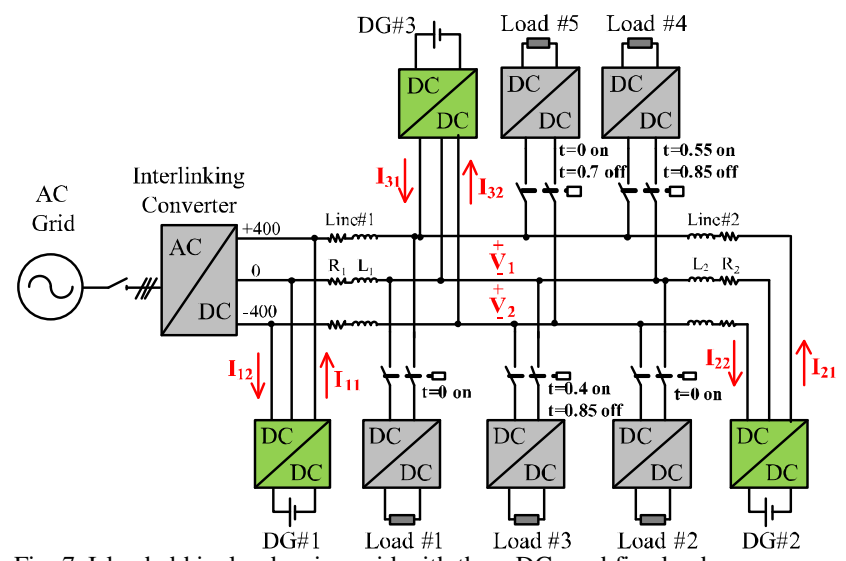

Fig. 7. Islanded bipolar de microgrid with three DGs and five loads

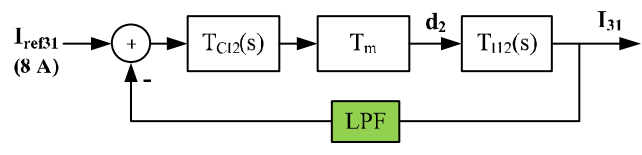

(a)

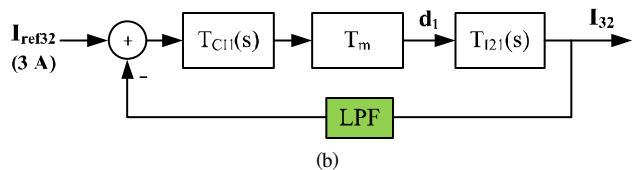

Fig. 8. Current-control loops of DG\#3, (a) upper terminal current loop, and (b) lower terminal current loop.

however, it works in the current-control mode. The control loops of the upper and lower terminals are shown, respectively, in Fig.8(a) and Fig.8(b), where the constatnt currents of $8 \mathrm{~A}$ and $3 \mathrm{~A}$ are injected to the upper and lower terminals, respectively. The design parameters of DG\#1, DG\#2, and DG\#3 are given in Table 1. All three DGs are simulated considering their detailed switching models. The microgrid accommodates five dc loads whose rated powers, rated currents, and switching times are given in Table 2. It should be noted that the nominal voltage of Load\#5 is $800 \mathrm{~V}$ (i.e., connected between $-400 \mathrm{~V}$ and $+400 \mathrm{~V}$ ) while Load\#1 Load\#2 are constant power loads connected to the upper and lower terminals, respectively. The impedances of line\#1 and line\#2 are assumed to be $R_{1}=0.5 \Omega$ and $L_{1}=200 \mu \mathrm{H}$, and

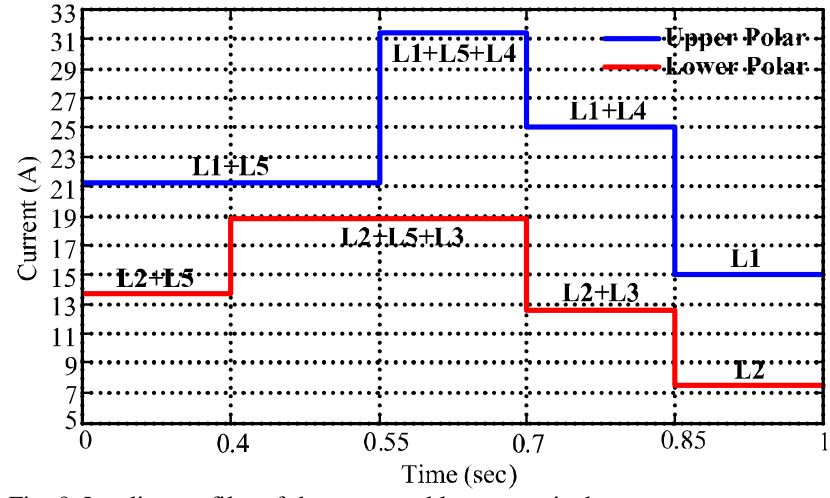

Fig. 9. Loading profiles of the upper and lower terminals.

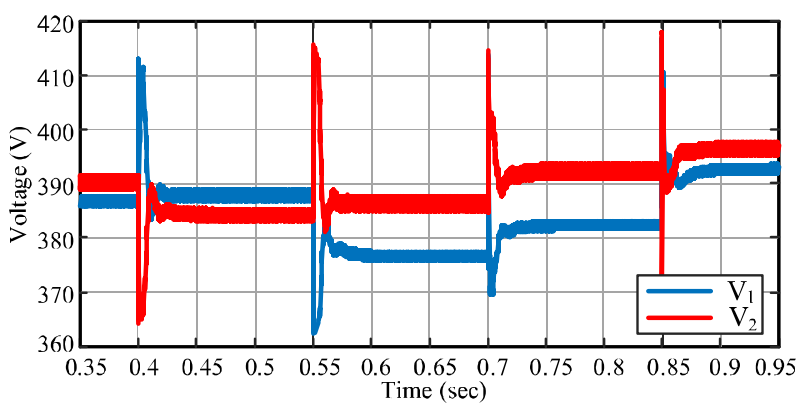

Fig. 10. Main busbar voltages; upper terminal $\mathrm{V}_{1}$ and lower terminal $\mathrm{V}_{2}$.

$R_{2}=0.4 \Omega$ and $L_{2}=170 \mu \mathrm{H}$, repectively. Making reference to (32), the droop gain values of DG\#1 and DG\#2 are

$$
k_{1}=k_{2}=\frac{400-380}{12.5}=1.6 \Omega
$$

The no-load voltage is considered to be $400 \mathrm{~V}$, while the lower limit of the nominal voltage, when the converter supplies the full-load current of $12.5 \mathrm{~A}$, is $380 \mathrm{~V}$. The two droop gains $k_{1}$ and $k_{2}$ will then be used to calculate references for the voltage control loops of DG\#1 and DG\#2 (each DG has two droop gains, see Fig.6). The loading profile of the upper and lower terminals are depicted in Fig.9. Subsequent to the considered loading, the main busbar voltages are shown in Fig.10. As it can be seen from this figure, the main busbar voltages (i.e., $V_{1}$ and $V_{2}$ in Fig.7) are not exactly regulated to $400 \mathrm{~V}$ due to the voltage drift imposed by the droop controller. However, voltages are kept balanced while the upper and lower terminals supply different load currents. The output currents of DGs are shown in Fig.11. The upper terminal loads are changed at $t=0.55,0.7$ and $0.85 \mathrm{sec}$. For instance, during the time interval $t=[0.55-0.7] \mathrm{sec}$, the load current is $31.25 \mathrm{~A}$, which ideally, DG\#1 and DG\#2 should supply the equal portion of $11.6 \mathrm{~A}$, as DG\#3 injects the remaining 8 A. However, the output currents 


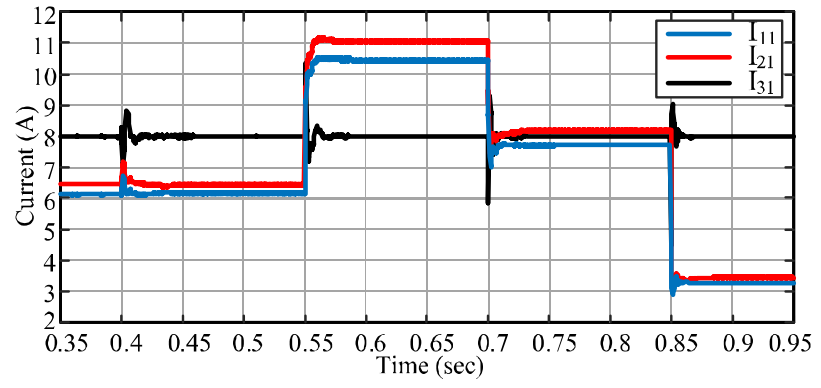

(a)

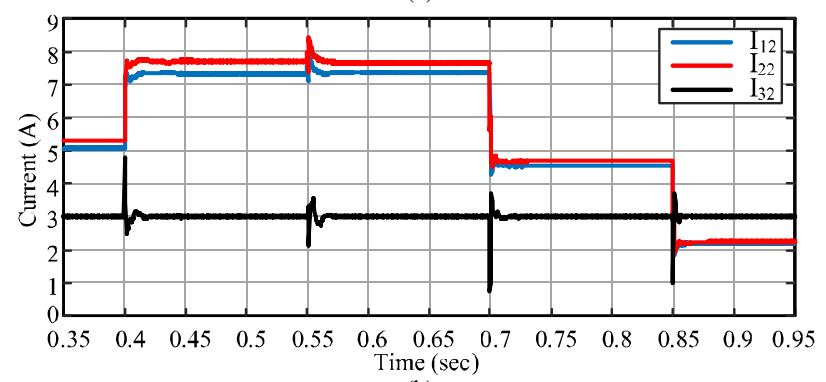

(b)

Fig. 11. DGs' output currents, (a) upper terminal currents, and (b) lower terminal currents.

of DG\#1 and DG\#2 are slightly different from the ideal value, which can be attributed to the effect of line impedances. The lower terminal currents $I_{12}, I_{22}$, and $I_{32}$ supplied by DG\#1, DG\#2, and DG\#3 respectively, are shown in Fig.11(b). DG\#1 and DG\#2 share the load current while DG\#3 supplies constant current of 3 A to this terminal.

To further evaluate the performance of the bipolar boost converter in voltage balancing, the voltages and currents of the upper and lower terminals of DG\#1 are shown in Fig.12(a) and (b), respectively. It can be seen that despite different loading profiles for the upper and lower terminals (for instance at $t=0.8 \mathrm{sec}$ ), the output voltages are kept within the allowable margin (i.e., 380-400 V).

\section{CONCLUSION}

In this paper a decentralized control strategy for voltage balancing and power sharing in bipolar dc microgrids was proposed. The microgrid DGs are interfaced with the grid by means of bipolar boost converters with the ability of boosting the input voltage and balancing the voltage of its two output terminals, particularly under unbalanced loading. Having done the small-signal analysis, the converter's transfer functions were derived. Using the RGA analysis, the highly coupled input-output pairs were identified, which helped to replace the MIMO control system of the converter by two SISO systems. To obtain a proper power sharing and voltage regulation in bipolar dc microgrid, the control system of each DG was modified by adopting a double droop control method. The

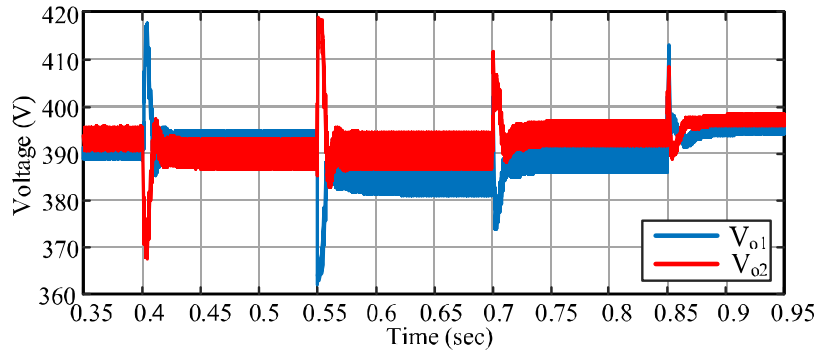

(a)

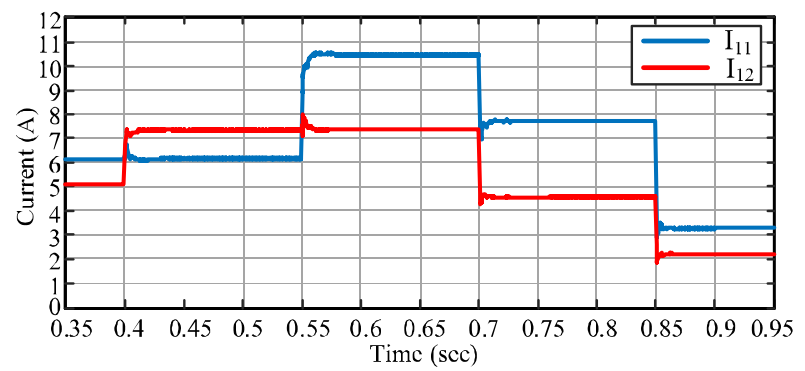

(b)

Fig. 12,Voltages and currents of bipolar boost converter DG\#1, (a) voltages of the upper and lower terminals, and (b) upper and lower terminals' currents.

effectiveness of the proposed topology and the double droop control strategy was evaluated through simulation studies conducted on an islanded bipolar dc microgrid involving unbalanced loads. From the simulation results, the proposed approach was found successful in providing a balanced voltage throughout the microgrid. By virtue of the proposed double droop control strategy, an accurate power sharing among the DGs in the host microgrid was obtained.

\section{REFERENCES}

[1] S. Anand, B. G. Fernandes, and J. M. Guerrero, "Distributed control to ensure proportional load sharing and improve voltage regulation in lowvoltage dc microgrids,“ IEEE Trans. Power Electron., vol. 28, pp. 19001912, April 2013.

[2] J. M. Guerrero, J. C. Vasquez, J. Matas, L. G. de Vicuna, and M Castilla, "Hierarchical control of droop-controlled ac and de microgrids: A general approach toward standardization," IEEE Trans. Ind. Electron., vol. 58, pp. 158-172, January 2011.

[3] N. Yang, D. Paire, F. Gao, A. Miraoui, and W. Liu, "Compensation of droop control using common load condition in DC microgrids to improve voltage regulation and load sharing," Int J Electr Power Energy Syst., vol. 64, pp. 752-760, January 2015.

[4] A. Bracale, P. Caramia, G. Carpinelli, E. Mancini, and F. Mottola,"Optimal control strategy of a DC micro grid," Int J Electr Power Energy Syst., vol. 67, pp. 25-38, May 2015.

[5] M. Hamzeh, M. Ashourloo, and K. Sheshyekani, "Modeling and Design of an Oscillatory Current Sharing Control Strategy in DC Microgrids," IEEE Trans. Ind. Electron., vol. 62, pp. 6647-6657, May 2015.

[6] N. Flourentzou, V. G. Agelidis, and G. D. Demetriades, "Vsc-based hvdc power transmission systems: An overview," IEEE Trans. Power Electron., vol. 24, pp. 592-602, March 2009. 
[7] M. Saeedifard, M. Graovac, R. F. Dias, and R. Iravani, "Dc power systems: Challenges and opportunities," in Proc. IEEE Power and energy society general meeting, Minneapolis, July 2010, pp. 1-7.

[8] D. Salomonsson, L. Soder, and A. Sannino, "An adaptive control system for a dc microgrid for data centers,” IEEE Trans. Ind. Appl., vol. 44, pp. 1910-1917, December 2008.

[9] J. Ciezki and R. W. Ashton, "Selection and stability issues associated with a navy shipboard dc zonal electric distribution system," IEEE Trans. Power Del., vol. 15, pp. 665-669, April 2000.

[10] H. Kakigano, Y. Miura, and T. Ise, "Low-voltage bipolar-type dc microgrid for super high quality distribution," IEEE Trans. Power Electron., vol. 25, pp. 3066-3075, December 2010.

[11] S. D. Tavakoli, J. Khajesalehi, M. Hamzeh, K. Sheshyekani, "Decentralised voltage balancing in bipolar dc microgrids equipped with trans-z-source interlinking converter," IET, Renewable Power Generation., doi: 10.1049/iet-rpg.2015.0222, January 2016.

[12] H. Kakigano, Y. Miura, T. Ise, and R. Uchida, "Dc voltage control of the dc micro-grid for super high quality distribution," in Proc. IEEE 4th Power Convers. Conf., (PCC'07), Nagoya, Japan, April 2007, pp. 518525.

[13] J. Lago, J. Moia, and M. L. Heldwein, "Evaluation of power converters to implement bipolar dc active distribution networks-dc-dc converters," in Proc. IEEE Energy Convers. Congr. Expo., Phoenix, AZ, September 2011, pp. 985-990.

[14] B. R. Lin, H. H. Lu, and Y. Hou, "Single-phase power factor correction circuit with three-level boost converter," in Proc. IEEE ISIE, Bled, July 1999, pp. 445-450.

[15] W. Li and X. He, "Review of nonisolated high-step-up dc/dc converters in photovoltaic grid-connected applications," IEEE Trans. Ind. Electron., vol. 58, pp. 1239-1250, April 2011.

[16] Y. Jang and M. M. Jovanvic, "New two-inductor boost converter with auxiliary transformer," IEEE Trans. Power Electron., vol. 19, pp. 169175, January 2004.

[17] C. E. Silva, R. P. Bascope, and D. S. Oliveira, "Proposal of a new high step-up converter for ups applications," in Proc. IEEE ISIE, Quebec, Canada, July 2006, pp. 1288-1292.

[18] Z. Hao, Z. Jing-hua, H. Bing, and T. Chao-nan, "A new interleaved three-level boost converter and neutral-point potential balancing," in Proc. IEEE 2nd sensor network and automation (IMSNA), Toronto, December 2013, pp. 1093-1096.

[19] R. W. Erickson and D. Maksimovic, Fundamentals of Power Electronics. Springer, 2012, ch. 8,9.

[20] G. C. Goodwin, S. F. Graebe, and M. E. Salgado, Control System Design. Prentice Hall, 2000, ch. 21.

[21] M. K. Kazimierczuk, Pulse-width Modulated DC-DC Power Converters. Wiley, 2008, ch. 12. 